\title{
GENERAL PRACTICE ON A NEW HOUSING ESTATE
}

BY

\author{
J. H. F. BROTHERSTON AND S. P. W. CHAVE \\ London School of Hygiene and Tropical Medicine
}

WITH

\section{A. CLEDWYN-DAVIES, A. S. HUNTER, D. A. LINDSAY, A. SCOTT, C. B. THOMSON, AND E. J. TRIMMER}

In recent years there has been an increasing recognition of the value that doctors' records can have in throwing light both on the working of general practice and on morbidity in the population. The present study consists of an analysis of the records kept by the general practitioners working on a new housing estate and forms part of an investigation into the health of a rehoused population.

\section{Materials AND Methods}

The estate is situated about 15 miles from the centre of London and was built by the London County Council between the years 1948 and 1952 as part of the post-war housing programme. It comprises just over 4,000 houses, with the necessary shops, schools, etc. Almost all the families on the estate came from Greater London. About twothirds of them were rehoused from the Council's waiting list, principally on the grounds of overcrowding or ill-health. The remainder transferred to the estate at their own request from other L.C.C. accommodation which they were occupying in the London area. The total population of about seventeen thousand consists mainly of couples with children, the average size of the families being four persons.

There are six doctors practising on the estate. Five of these form a partnership, two members of which also have surgeries off the estate. About 13,000 people are registered with this partnership, which is conducted from two surgeries on the estate, each having two consulting rooms and a common waiting-room. The sixth doctor has about 3,000 patients on his list and practises from a house which he occupies on the estate.
For the purpose of this study, all six doctors adopted a simple system of record keeping, using a modified form of the National Health Service card. In respect of each consultation, the doctor recorded on the patient's card the date, place, diagnosis or other reason for attendance, treatment, certificates issued, and details of any referral.

The recording system was brought into use about 2 months before the beginning of the year 1953, in order to allow the practitioners to familiarize themselves with the procedure. No difficulties arose in recording consultations made in the surgeries, but it is possible that the reporting of home visits was somewhat less reliable. Four of the doctors recorded home visits on slips from which the entries were afterwards transcribed on to the patients' cards by a secretary. The other two doctors preferred to take the patients' cards with them and complete them at the time of the consultations. On some occasions, however, the visits were made in response to a telephone message or note, asking the doctor to call but without giving the patient's name. Where this occurred, the doctor recorded the consultation and entered it on the card after his return to the surgery. In the course of the day-to-day working of busy practices, it is possible that certain errors were introduced but they are likely to have been small.

\section{The SAMPLe}

Almost all the patients on the doctors' lists were resident on the estate and those who were not residents (224 registered with the partnership, and 12 with the other doctor) have been omitted from this study.

A 25 per cent. sample of the addresses on the estate was drawn using a set of random numbers, and the 
analysis was carried out on the records of the registered patients who lived at those addresses during the year 1953. The information on the record cards was then coded, transferred to punch cards, and sorted mechanically.

There were 1,018 addresses in the sample. Owing to removals, 77 of these houses had two families living in them during the year, making a total of 1,095 families comprising 4,749 persons. These families ranged in size from one to eleven, with an average of $4 \cdot 3$ persons. About half of the families consisted of either four or five persons. In nearly three-quarters of the families in the sample every member was registered with a doctor on the estate for at least some part of the year. A further 17 per cent. of the families had some, but not all, members registered, and 9 per cent. had no-one registered with a doctor on the estate.

Thus, of the 4,749 persons in the sample addresses, 4,067 ( 86 per cent.) were registered with the doctors on the estate. About 18 per cent. of the total registered population were on the doctors' lists for less than 12 months of the year, the average duration for all patients being 10.9 months. 80 per cent. of the patients were registered with the partnership, and the remainder with the doctor who practised alone. Only ten patients in the sample consulted with both practices.

As would be expected in a community of this kind, the size of the practices fluctuated very little throughout the year; the average registered population in the sample, based on the actual numbers at the end of each quarter, was 3,710 .

\section{RESUlts}

Description of the Registered Population.Table I shows that the distribution of age groups in the practice population differed appreciably from that of Greater London and from that of England and Wales as a whole. The principal characteristics of this rehoused population were the high proportion of young children and the relatively small number of old persons. These features, which are common to all new housing estates, are likely to affect the nature of the sickness occurring among the population.

TABLE I

AGE DISTRIBUTION OF REGISTERED POPULATION

\begin{tabular}{|c|c|c|c|}
\hline$\underset{\text { (yrs) }}{\text { Age Group }}$ & $\begin{array}{l}\text { Registered } \\
\text { Population } \\
\text { (per cent.) }\end{array}$ & $\begin{array}{c}\text { Greater } \\
\text { London } \\
\text { (per cent.) }\end{array}$ & $\begin{array}{l}\text { England } \\
\text { and Wales } \\
\text { (per cent.) }\end{array}$ \\
\hline $\begin{array}{c}0-4 \\
5-14 \\
15-44 \\
45-64 \\
65 \text { and Over }\end{array}$ & $\begin{array}{r}13 \cdot 2 \\
25 \cdot 1 \\
43 \cdot 2 \\
9 \cdot 0 \\
3 \cdot 1\end{array}$ & $\begin{array}{r}8 \cdot 2 \\
12 \cdot 5 \\
44 \cdot 0 \\
24 \cdot 6 \\
10 \cdot 7\end{array}$ & $\begin{array}{r}8 \cdot 5 \\
13 \cdot 7 \\
42 \cdot 8 \\
24 \cdot 1 \\
10 \cdot 9\end{array}$ \\
\hline $\begin{array}{l}\text { No Record except } 21 \\
\text { and over } \because . . \\
\text { No Records all } \quad \ldots\end{array}$ & $\begin{array}{l}3.7 \\
2 \cdot 7\end{array}$ & 二 & 二 \\
\hline$\ldots \quad \ldots$ & $100 \cdot 0$ & $100 \cdot 0$ & $100 \cdot 0$ \\
\hline
\end{tabular}

Table II shows the proportion of females among the registered patients, in Greater London, and in England and Wales. There are slight differences in certain age groups.

TABLE II

PROPORTION OF FEMALES

\begin{tabular}{|c|c|c|c|c|}
\hline $\begin{array}{c}\text { Age Group } \\
\text { (yrs) }\end{array}$ & & $\begin{array}{c}\text { Registered } \\
\text { Population } \\
\text { (Per cent. } \\
\text { Fermale) }\end{array}$ & $\begin{array}{c}\text { Greater } \\
\text { London } \\
\text { (Per cent. } \\
\text { Female) }\end{array}$ & $\begin{array}{c}\text { England and } \\
\text { Wales, 1951 } \\
\text { (Per cent. } \\
\text { Female) }\end{array}$ \\
\hline $\begin{array}{c}0-4 \\
5-14 \\
15-44 \\
45-64 \\
65 \text { and Over }\end{array}$ & & $\begin{array}{l}50 \cdot 6 \\
50 \cdot 8 \\
53 \cdot 2 \\
49 \cdot 2 \\
57 \cdot 1\end{array}$ & $\begin{array}{l}50 \cdot 2 \\
49 \cdot 0 \\
52 \cdot 6 \\
54 \cdot 2 \\
61 \cdot 2\end{array}$ & $\begin{array}{l}49 \cdot 0 \\
49 \cdot 0 \\
50.6 \\
53.7 \\
58.5\end{array}$ \\
\hline All Ages & .. & $51 \cdot 8$ & $53 \cdot 2$ & $52 \cdot 0$ \\
\hline
\end{tabular}

Table III shows the social class distribution of the principal wage-earners of the 998 families to which the registered patients belonged, and that of occupied males in Greater London and England and Wales. Although differences in age do not permit a strict comparison, certain features of the social class composition of the estate population are worth noting. Families in Social Class III predominate and the proportions in Social Classes I and II are much smaller, and that in Social Class V a little smaller than in Greater London and England and Wales.

TABLE III

SOCIAL CLASS DISTRIBUTION

\begin{tabular}{|c|c|c|c|}
\hline Social Class & $\begin{array}{l}\text { Registered } \\
\text { Population* } \\
\text { (per cent.) }\end{array}$ & $\begin{array}{l}\text { Greater } \\
\text { Londont } \\
\text { (per cent.) }\end{array}$ & $\begin{array}{c}\text { England and } \\
\text { Walest } \\
\text { (per cent.) }\end{array}$ \\
\hline $\begin{array}{c}\text { I, II } \\
\text { III } \\
\text { IV } \\
\text { Retired, Disabled, and } \\
\text { No Record }\end{array}$ & $\begin{array}{r}6 \cdot 3 \\
64 \cdot 4 \\
10 \cdot 8 \\
8 \cdot 2 \\
10 \cdot 3\end{array}$ & $\begin{array}{l}21 \cdot 4 \\
54 \cdot 7 \\
10 \cdot 7 \\
13 \cdot 2 \\
-\end{array}$ & $\begin{array}{l}19 \cdot 1 \\
51 \cdot 4 \\
16 \cdot 3 \\
13 \cdot 2 \\
-\end{array}$ \\
\hline$\ldots \quad \ldots$ & $100 \cdot 0$ & $100 \cdot 0$ & $100 \cdot 0$ \\
\hline
\end{tabular}

* Principal wage-earners of patients' families.

† Males aged 15 and over.

Half of the principal wage-earners were engaged on skilled manual work, and about one-fifth in nonmanual work, of whom about one-third were clerical workers.

Just over one-third of the total registered population was gainfully employed, and 30 per cent. of these were working in engineering trades, metal manufacture, transport, or communications. About 40 per cent. of the total patients were schoolchildren or pre-schoolchildren, and a further 18 per cent. were housewives who did not go out to work.

Consultations. - In this investigation, a "consultation" included not only a meeting between the 
patient and the doctor at the surgery or in the home, but also treatment or advice given in response to a message received by note or telephone.

During the year, 76 per cent. of the registered population in the sample consulted the doctor at least once. The consultation rate is a unit of measurement that has been commonly employed in studies of general practice to assess the extent to which the service is utilized. There is, however, at the present time, no generally accepted base for the calculation of rates of this kind. Accordingly, in this paper, the rates will be expressed as the average number of consultations per patient per annum based on:

(i) the total practice population;

(ii) the average number of patients on the lists, calculated from the actual numbers registered at the end of each quarter;

(iii) the number of patients who consulted during the year.

The total number of consultations among the 3,081 patients who consulted was 15,286 . This gives consultation rates for the sample population of 3.8 per person registered, $4 \cdot 1$ per person based on the average registered population, and 5 per person consulting. These figures may be compared with 5 consultations per person registered found in the studies of Bradford Hill (1951) and McGregor (1950), 5 per person based on the average registered population and 7 per person consulting reported by Backett, Heady, and Evans (1952), and 3.3 per person based on a mid-year registered population found by Fry (1952). Logan (1953), reporting on eight practices, found a range of from $2 \cdot 9$ to $4 \cdot 7$ consultations per person based on the average registered population.

Since 45 per cent. of the families on the estate had been granted some priority for rehousing on medical grounds, it might have been expected that their consultation rates would have exceeded those in other areas. That this was not so is partly due to the low mean age of the population.

Fig. 1 shows the consultation rates per 100 average registered population by sex and age group.

Although the older patients consulted the doctor more often than the young ones, the fact that old people formed only a small proportion of the population meant that their demands on the doctors accounted for a much smaller fraction of the consultations that took place. Patients under 15 accounted for 36 per cent., and those between 15 and $\mathbf{4 4}$ for $\mathbf{4 5}$ per cent. of all consultations. Thus four out of five consultations were made by people under

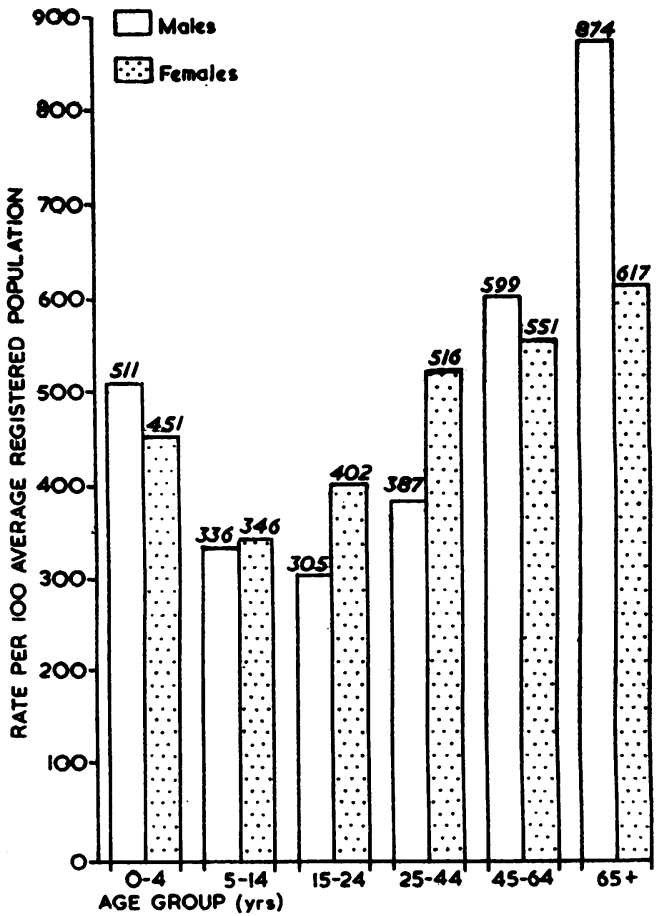

Fig. 1.-Consultation rate per hundred persons registered by sex and age group.

45 years of age. The patients aged 65 and over, i.e., those whose consultation rates were by far the greatest, made little more than 5 per cent. of the total consultations. Women made more consultations than men (54 and 46 per cent. respectively) and more than one-quarter of all consultations were made by women aged 15 to 44 .

About one-quarter of the registered patients did not consult the doctor at all during the year (males 27 per cent. and females 22 per cent.). A further 38 per cent. who did consult had less than four consultations (Fig. 2, opposite).

In each of the four age groups, 0-14, 15-44, 45-64, and 65 and over, about 16 per cent. of patients accounted for half the consultations. Nearly 7 per cent. of all registered patients consulted the doctor on twelve or more occasions, and accounted for 30 per cent. of the total. This state of affairs has been reported in other studies of general practice.

When the registered patients were classified according to the social class of the principal wageearner of each family, a slight social gradient appeared in the use of the general practitioner services. The average number of consultations per person increased from $\mathbf{3 . 2}$ for Social Classes I and II 


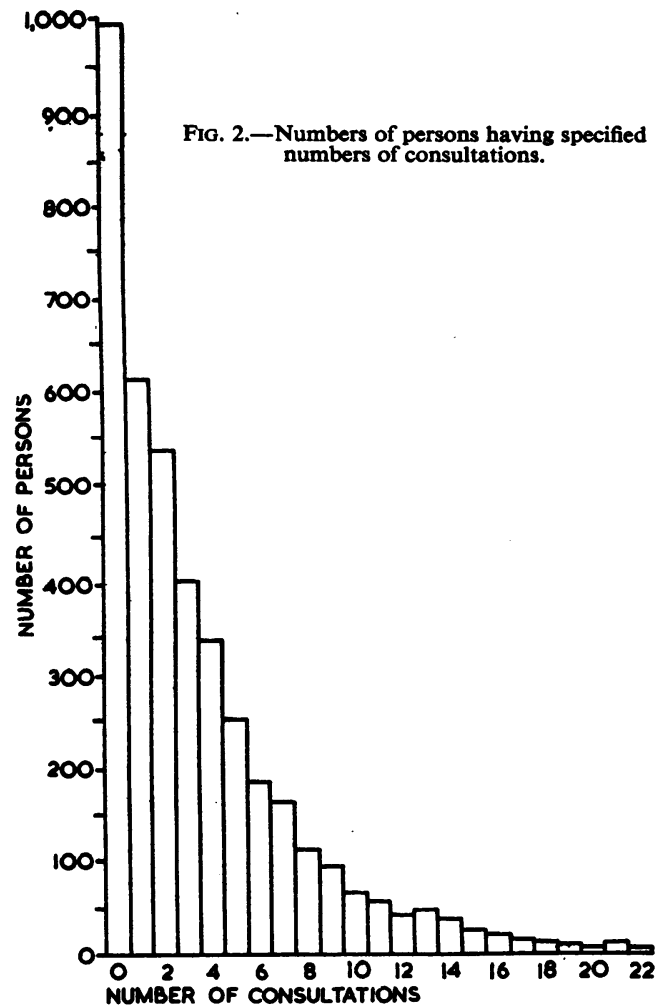

to 3.8 for Social Class V (Table IV). These differences are statistically significant, but 6 per cent. of the registered patients were not assigned to a social class. These were patients from families dependent on pensions and allowances and those for whom the relevant information was not obtained. Since this group included most of the elderly patients, the consultation rate was higher than that for the classified groups.

TABLE IV

CONSULTATION RATES AND ILLNESS RATES BY SOCIAL CLASS

\begin{tabular}{c|c|c|c|c|c|c}
\hline \multirow{2}{*}{ Social Class .. } & I and II & \multicolumn{2}{|c|}{ III } & IV & V & $\begin{array}{c}\text { No } \\
\text { Record }\end{array}$ \\
\cline { 2 - 6 } & $c^{*}$ & $a, b, d, e$ & & & \\
\hline $\begin{array}{c}\text { Consultation } \\
\text { Rate }\end{array}$ & 3.2 & 3.3 & 3.7 & 3.7 & 3.8 & 4.9 \\
\hline IIIness Rate .. & 2.1 & 2.0 & 2.4 & 2.3 & 2.4 & 2.6 \\
\hline \multicolumn{6}{c}{$c=$ clerical }
\end{tabular}

Seventy consultations ( 0.46 per cent.) took place between $8 \mathrm{p} . \mathrm{m}$. and $8 \mathrm{a} . \mathrm{m}$., which is considerably less than the 0.79 per cent. reported by Backett, Heady, and Evans (1952) and the 0.75 per cent. reported by Fry (1952).
EPISODES OF IlLNESS.-The definition of an episode of illness implies some reference to time, but the measurement of duration of sickness is fraught with difficulty. In most instances neither onset nor termination is clearly defined. On the other hand, the period during which the patient is under medical care can be established, and can be used both to define an episode of illness and to measure its duration. It can also be used to find the number of episodes of illness in a population, and to compare the effects of different diseases and the behaviour of different age groups.

Accordingly, in this study, the duration of an episode of sickness has been defined as the period between the first and last consultations for that episode, including consultations for debility following the illness. Where a person was suffering from more than one disease at the same time, the duration of each episode was measured in the same way, treating the conditions separately. If there was only one consultation, the episode was regarded as lasting for one day. In chronic conditions, an episode was regarded as continuing so long as the patient was under care. For chronic diseases not needing continuous supervision, exacerbation of illness was considered to mark the onset of a new episode.

During the year there were 9,479 episodes of illness among 3,043 patients: $2 \cdot 3$ per person registered, 2.6 per person based on the average registered population, and $3 \cdot 1$ per person consulting.

The distribution of the number of episodes of illness among the total registered population is shown in Fig. 3. One-quarter had no illness, about one-half had from one to three illnesses, and the

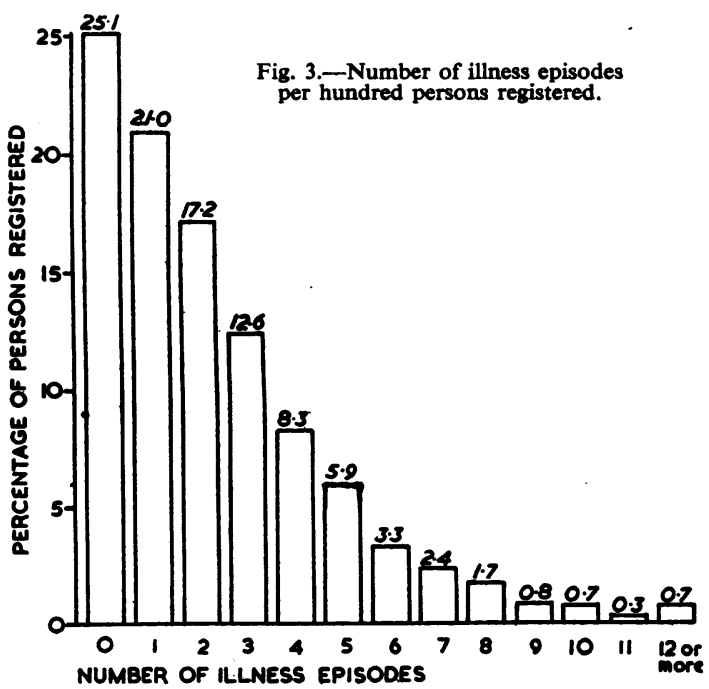


remaining quarter had four or more illnesses during the year. About 5 per cent. of the registered population had more than seven illnesses in the 12 months.

Fig. 4 shows the illness rates (per 100 average registered population) by sex and age group. Among males the rate fell from infancy to adulthood and then increased with age. For females, the rate fell from infancy to adulthood, rose steeply for the next 20 years, and remained relatively steady thereafter.

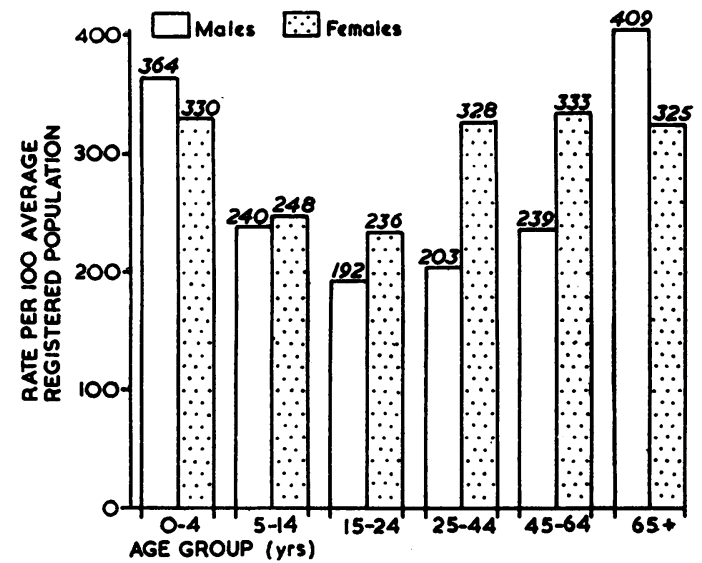

Fig. 4.-Illness episodes per hundred persons registered by sex and age group

In infancy and old age illness rates were higher for males than for females; at all other ages the female rates were greater. Figs 1 and 4, showing the consultation and illness rates, show that the young adult males (15-44) were the most healthy and the men aged 65 and over the least healthy. This is not in accord with the findings of other workers. The records of the housing authority showed that 34 per cent. of the men aged 65 and over had been granted priority for rehousing on medical grounds, compared with only 18 per cent. of the women. The incidence of chronic conditions and defects recorded at the first consultation was 57 and 30 per cent. for elderly men and elderly women respectively.

In the age group 45-64, men had fewer illnesses but more consultations than women. The higher consultation rate for men was largely due to the fact that most of them had to obtain National Insurance certificates during illness. For this age group, 23 National Insurance certificates were issued for every 100 males registered, compared with 5 certificates for every 100 females ( 1 certificate for every 2.4 consultations for men, as against 1 for every 10 consultations for women). This suggests that the requirements of the present system of National Insurance benefits tend to increase the number of consultations made by wage-earning patients.
Among patients who consulted during the year, about 80 per cent. had an average of from one to three consultations for each episode of sickness; 3 per cent. had five or more.

The number of consultations per illness appeared to increase with age. For males it rose from an average of 1.4 consultations per illness at age $0-4$, to 2.5 at age $45-64$, and fell to $2 \cdot 1$ for 65 and over. For females the average was 1.4 consultations per illness at ages $0-4$ and increased to 1.9 at 65 and over.

The number of consultations per illness fell slightly as the number of illnesses increased (1.9 for patients having one illness, 1.5 for patients having five illnesses, and 1.3 for patients having twelve or more). This trend was probably influenced by the fact that multiple conditions could often be treated together at the same consultation.

The social gradient was less marked for illnesses than for consultations (Table IV).

DURATION OF SiCKNESS. -70 per cent. of all episodes of illness were dealt with by single consultations and were thus regarded as being under care for one day. Nearly one-quarter of the episodes lasted for from 2 to 30 days, 7 per cent. for more than 30 days and only 3 per cent. for more than 90 days.

By adding together the number of days that each patient was under care, it is possible to obtain an assessment of the total period of sickness for each person during the year. Although this is an exceedingly rough measure, it does allow certain comparisons to be made.

The distribution of total days' sickness among the registered population is shown in Table V. More than half the patients were under care for less than 5 days, one-quarter for from 5 to 30 days, and only about 8 per cent. for more than 90 days.

TABLE V

\begin{tabular}{c|c} 
DAYS OF SICKNESS, UNDER CARE, DURING \\
\hline $\begin{array}{c}\text { Days of Sickness } \\
\text { under Care }\end{array}$ & $\begin{array}{c}\text { Percentage of } \\
\text { Registered Population }\end{array}$ \\
\hline 0 & 25.1 \\
$1-4$ & 32.6 \\
$5-14$ & 15.1 \\
$15-30$ & 9.7 \\
$31-90$ & 9.8 \\
More than 90 & 7.7 \\
\hline
\end{tabular}

If the number of days' sickness is compared by sex and age group, the outstanding feature among males is a steady increase with age in those having more than 30 days' sickness (from 11 per cent. in males under 15 , to 47 per cent. at 65 and over). Among females the rate increased from 10 per cent. 
for those under 15 to 33 per cent. for those aged $45-64$, and then fell slightly to 30 per cent. for those aged 65 and over.

CerTificates.-About one certificate was issued for every patient consulting and one certificate for every five consultations. About two-thirds of these certificates were required by the National Insurance regulations.

PresCriptions.-The prescription rate may be regarded as one measure of the treatment received by the patient. In this study each item of treatment prescribed was regarded as a single prescription. 15,098 prescriptions were issued to 2,898 patients in the sample, 99 prescriptions for every 100 consultations. The prescription rates were 3.7 per person registered, 4.1 per person based on the average registered population, and 4.9 per patient consulting. These rates approximate closely to the consultation rates and are almost identical with those reported by Backett, Heady, and Evans (1954).

Only about 5 per cent. of the registered population consulted the doctor without obtaining prescriptions and most of these consultations were for reasons other than sickness. Nearly one-quarter of the patients had one or two prescriptions and accounted for about 10 per cent. of all the prescriptions issued.

10 per cent. of patients had ten or more prescriptions, and accounted for 38 per cent. of the total. A small group ( 1.5 per cent.) had twenty or more prescriptions (11 per cent. of the total number issued).

56 per cent. of the prescriptions were issued to females. The trends with age in the prescription rates for the two sexes (shown in Table VII, below) are similar to those in the consultation rates, except that the male patients aged 45-64 had fewer prescriptions but more consultations than the females. The young adult males (15-24 years) had the fewest prescriptions, whereas the men aged 65 and over had proportionately more than any other group.

ReFERRALS.-During the year there were 31 referrals for every 100 patients registered. This figure approximates to the 35 per 100 reported by Backett, Heady, and Evans (1954). In the eight practices studied by Logan (1953) the referral rates per 100 practice populations ranged from 6.4 to 33 (average about 16).

Table VI shows that 70 per cent. of all referrals were to hospitals as out-patients and 10 per cent. as in-patients. ${ }^{*}$

* An in-patient referral relates to a person sent as an inpatient by the doctor but not necessarily accepted as such by the hospital. It is a statement of the doctor's intention rather than of what may actually statement of th
have occurred.
TABLE VI

REFERRALS

\begin{tabular}{|c|c|c|c|c|c|}
\hline \multirow{2}{*}{\multicolumn{2}{|c|}{ Type of Referral }} & \multicolumn{2}{|c|}{ Hospital } & \multirow{3}{*}{$\begin{array}{c}\text { “Other" } \\
240\end{array}$} & \multirow{3}{*}{$\begin{array}{l}\text { Total } \\
1,162\end{array}$} \\
\hline & & \multirow{2}{*}{$\begin{array}{c}\begin{array}{c}\text { In- } \\
\text { patient }\end{array} \\
113 .\end{array}$} & \multirow{2}{*}{$\frac{\begin{array}{c}\text { Out- } \\
\text { patient }\end{array}}{809}$} & & \\
\hline \multirow{2}{*}{ Referrals } & No. & & & & \\
\hline & Per cent. & 10 & 70 & 20 & 100 \\
\hline \multirow{2}{*}{ Persons } & No. & 109 & 658 & 223 & 909 \\
\hline & Per cent. & 12 & 72 & 26 & \\
\hline
\end{tabular}

About a quarter of the patients who consulted were sent to hospital, and four out of every five of these went as out-patients. Nearly one in five of the people who were sent as out-patients were referred more than once, although not necessarily for the same illness.

Rather more women then men were sent to hospital, 57 per cent. of the people referred as inpatients and 54 per cent. of the out-patients being females.

Hospital referral rates were 18.3 per 100 patients registered, 20 per 100 based on the average registered population, and 24 per 100 patients consulting.

Fig. 5 shows referral rates to hospitals by age and sex based on the average registered population. For males the rates rose steadily with age; for females they increased to ages 45-64, and then fell.

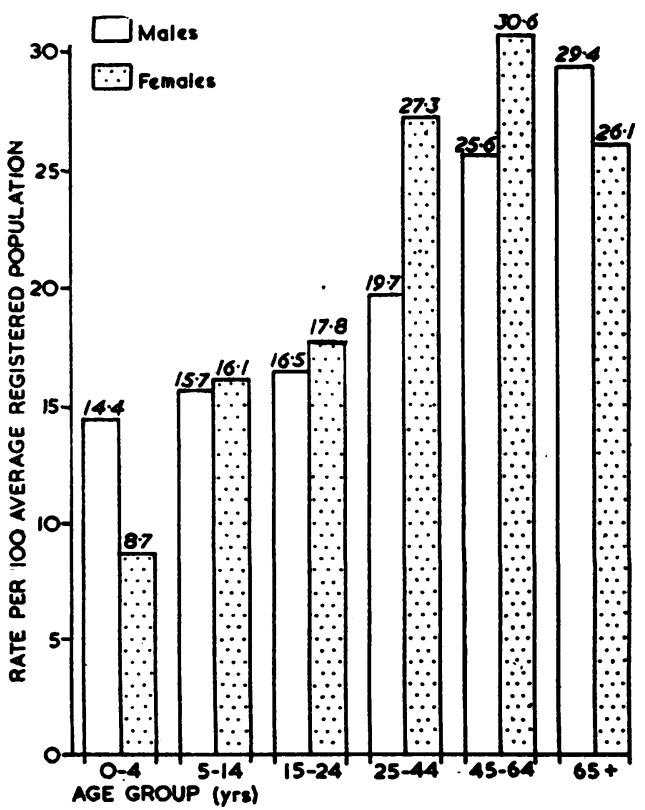

FiG. 5.-Referrals to hospital per one hundred persons registered by sex and age group. 
One-fifth of the referrals were to agencies other than hospitals; 34 per cent. of these "other" referrals were to ophthalmologists and opticians, 28 per cent. to district nurses, and 17 per cent. to dental surgeons. The remainder included referrals to hospital for blood counts, or to health visitors, and specimens sent to hospital laboratories for diagnostic tests.

\section{Discussion}

The population of this housing estate had certain characteristics which would be expected to influence the incidence of sickness and hence the extent to which the services of the general practitioners would be utilized. A considerable proportion of the families had been rehoused on grounds of ill-health, generally of a chronic nature, a factor which would tend to increase the usage of the local medical services. On the other hand, the age composition of the estate population, with its high proportion of school-children and relatively small number of old people, would be likely to reduce the extent of sickness below that of a more representative sample of the general population. The application to the doctors' records of four yardsticks (the rates for consultation, illness, prescription, and hospital referral) suggests that these two influences have brought about a degree of usage of the general practitioner services which differs little from that found in other areas.

Indeed, a significant feature of the results of this inquiry is the considerable agreement with the findings of other workers in this field, notably those of Fry (1952), Logan (1953), and Backett, Heady, and Evans (1954). In all these studies, about threequarters of the registered patients consulted in the course of 12 months, an average of from three to five consultations per person. There was more work among women than men, and more work among the old than the young. The healthiest group comprised the adolescent and young adult males.

In the estate population, the highest rates for consultations, illnesses, prescriptions, and hospital referrals occurred among the men aged 65 and over (Table VII). Fry (1952), Logan (1953), and Backett, Heady, and Evans (1954) all reported higher consultation rates among the women of this age group. It is probable that the rehousing process entails some factor of selection which would account for this difference. Most women of this age still have housekeeping responsibilities. If unfit, an elderly housewife would be unlikely to seek to be rehoused on an outlying estate, but this would not necessarily be true of an elderly unfit husband. Support for this view is provided by the observation that more elderly men than elderly women had medical priority for rehousing and that the incidence of chronic medical conditions and defects recorded at the patients' first consultations was higher for males of this age than for females. The small number of old people living on this estate are evidently unrepresentative of their age group.

\section{TABLE VII}

CONSULTATION, ILLNESS, PRESCRIPTION, AND HOSPITAL REFERRAL RATES PER PERSON, BASED ON THE AVERAGE REGISTERED POPULATION

\begin{tabular}{|c|c|c|c|c|c|}
\hline$\underset{\text { (yrs) }}{\text { Age- }}$ & Sex & $\begin{array}{c}\text { Consulta- } \\
\text { tion } \\
\text { Rate }\end{array}$ & $\begin{array}{l}\text { Illness } \\
\text { Rate }\end{array}$ & $\begin{array}{c}\text { Prescrip- } \\
\text { tion } \\
\text { Rate }\end{array}$ & $\begin{array}{c}\text { Hospital } \\
\text { Referral } \\
\text { Rate }\end{array}$ \\
\hline \multirow[t]{2}{*}{$0-4$} & Male & $5 \cdot 1$ & $3 \cdot 6$ & $5 \cdot 0$ & $0 \cdot 14$ \\
\hline & $\overline{\text { Female }}$ & 4.5 & $3 \cdot 3$ & $4 \cdot 6$ & 0.09 \\
\hline \multirow{2}{*}{$5-14$} & Male & 3.4 & $2 \cdot 4$ & $3 \cdot 3$ & $0 \cdot 16$ \\
\hline & Female & 3.5 & $2 \cdot 5$ & 3.4 & $0 \cdot 16$ \\
\hline \multirow{2}{*}{$15-24$} & Male & $3 \cdot 1$ & 1.9 & $2 \cdot 7$ & 0.17 \\
\hline & Female & $4 \cdot 0$ & $2 \cdot 4$ & $3 \cdot 2$ & $0 \cdot 18$ \\
\hline \multirow{2}{*}{$25-44$} & Male & 3.9 & $2 \cdot 0$ & $3 \cdot 1$ & $0 \cdot 20$ \\
\hline & Female & $5 \cdot 2$ & $3 \cdot 3$ & 4.9 & 0.27 \\
\hline \multirow{2}{*}{$45-64$} & Male & $6 \cdot 0$ & $2 \cdot 4$ & $5 \cdot 0$ & 0.26 \\
\hline & Female & $5 \cdot 5$ & $3 \cdot 3$ & $5 \cdot 7$ & 0.30 \\
\hline \multirow{2}{*}{$\begin{array}{l}65 \text { and } \\
\text { Over }\end{array}$} & Male & 8.7 & $4 \cdot 1$ & 8.6 & 0.30 \\
\hline & Female & $6 \cdot 2$ & $3 \cdot 3$ & $7 \cdot 1$ & 0.26 \\
\hline
\end{tabular}

The concentration of work among a relatively small proportion of the patients is another common feature of general practice. In this study, as in that of Backett, Heady, and Evans (1954), 16 per cent. of the registered patients accounted for one-half of the consultations. The 7 per cent. of patients who took up 30 per cent. of the consultations represent the "hard core" of the doctors' work. Further attention will be given to this group in a later stage of this investigation.

Examination of the period under care is a tentative attempt to introduce measurement into an important but difficult aspect of morbidity studies. It has been of value here in revealing the large proportion of illnesses which doctors saw only once and the small proportion treated over a long period. It showed that more than half of the registered patients were under care for less than 5 days in the year, and the extent to which duration of sickness is a function of age. Further use will be made of this measure in the succeeding stages of the analysis, which will be concerned with the nature of the sickness occurring in the sample population. 
In studies of this kind there is need for agreement on the way in which the information is to be presented. This is particularly true in regard to such matters as the calculation of consultation rates. Hitherto, a variety of denominators has been employed, including the total practice population, the number of patients consulting, and the numbers at risk at the mid-year. In this paper use has been made of the average registered population calculated from the actual numbers of patients on the lists at the end of each quarter. While each of these denominators has certain advantages, it is also desirable that there should be a generally accepted basis for the determination of rates.

The task of keeping the records was not found to be unduly onerous by the practitioners concerned and was carried out with the minimum of clerical help. In the course of time, however, the records were found to be of assistance in providing an up-to-date medical history of the patients. They were particularly helpful to the members of the partnership, where at least half of the patients consulting were seen by more than one doctor, and 14 per cent. saw three or more doctors in the year. This is likely to be a characteristic that is common to partnership practice of this kind, and it is one in which a simple system of record keeping can be especially useful.

The value of such a system to the doctors themselves and for research purposes, which has been noted by others, has been confirmed by this study.

\section{SUMmaRY}

An analysis has been carried out of the records kept for the year 1953 by six doctors practising on a new housing estate near London. The population of the estate is described in terms of age, sex, and social class.

76 per cent. of the registered patients consulted a doctor at some time during the year, the consultation rate per person being $4 \cdot 1$ based on the average registered population; females had more consultations than males; 80 per cent. of all consultations were made by people under the age of 45 .

One-sixth of the patients accounted for about half of the consultations, and 30 per cent. of the consultations were made by the 7 per cent. of registered patients who consulted twelve or more times in the year. The consultation rates showed a slight, but statistically significant, social gradient, with more consultations among patients in the lower social classes.

The illness rate was 2.6 per person, and was higher among males in infancy and old age, and among females between the ages of 5 and 64 .

A method of estimating the duration of sickness in terms of the period under medical care was employed. This showed that 70 per cent. of all illnesses were dealt with in single consultations, and that only 3 per cent. of illnesses were under care for more than 90 days. Over half of the practice population were under care for less than 5 days, and only 8 per cent. for more than 90 days.

The proportion of patients having more than 30 days sickness generally increased with age, but there was a slight fall among the women aged 65 and over.

Certificates were issued at the rate of about one for every five consultations, two-thirds of these being necessitated by the requirements of the National Insurance regulations.

Prescriptions were issued at the rate of about one per consultation, the prescription rate being $4 \cdot 1$ per person. Only 5 per cent. of the practice population consulted the doctor but did not obtain a prescription.

About 30 per cent. of the patients who consulted a doctor were referred outside the practices, 80 per cent. of all referrals being to hospitals, either as inpatients or as out-patients. The person-hospital referral rate was 20 per 100 , and there were 31 referrals for every 100 registered patients.

Males over 65 had the highest rates for consultations, illnesses, prescriptions, and referrals. The reason for this is discussed.

The value of record-keeping by general practitioners is stressed, together with the need for a generally accepted method of expressing rates in studies of this kind.

We should like to thank Professor J. M. Mackintosh for his constant support and encouragement, and Miss Jane Cooper and her assistants whose management of the records has made this study possible.

\section{REFERENCES}

Backett, E. M., Heady, J. A., and Evans, J. C. G. (1954). Brit. med. J., 1, 109.

Fry, J.' (1952). Ibid., 2, 249.

Hill, A. Bradford (1951), J. roy. statist. Soc., 114, 1.

Logan, W. P. D. (1953). "Studies on Medical and Population Subjects, No. 7". General Register Office, H.M.S.O., London. McGregor, R. M. (1950). Edinb. med. J., 57, 433. 